\title{
Multivariate Analysis of the Impact of Gender and College Major on Student levels of Environmental Concern and Knowledge
}

\author{
Timothy A. Goodale* \\ Elizabeth City State University \\ Elizabeth City, NC, USA
}

\begin{abstract}
Knowledge and stewardship are essential factors in developing perceptions of the environment. This research determines if gaps in environmental knowledge and concern exist between genders as well as students majoring in science and those seeking non-science degrees. Approximately 1,229 first-year university students participated in this study. Environmental concern is measured with the New Ecological Paradigm and the Environmental Concern Scale. Total Environmental Knowledge is measured by a scale of 24 academic questions based on environmental sciences and behaviors. Outcomes of the study determined the strength of interactions between multiple factors such as gender, race, residential status and college major that potentially impact environmental knowledge, actions and behaviors. Findings suggest that females and science majors express higher levels of environmental concern.
\end{abstract}

Keywords: Gender, College Major, Environmental Concern, Environmental Knowledge, New Ecological Paradigm.

\section{Introduction}

Environmental conditions affect everyone and an informed public is essential to establish sound environmental policy and stimulate environmental improvement. Vital components in developing positive perceptions of the environment include adequate levels of environmental knowledge and stewardship. Environmental education and stewardship initiatives occur on many levels but are rarely rigorously assessed for impact on a multivariate level. College campuses are teeming with perceptional differences about current and future global environmental health. Previous research has generally found that college students pursuing science majors will have an increased environmental concern and knowledge compared to their non-science counterparts. Additionally, research has found that females demonstrate a greater involvement and are more concerned with environmental issues. This potential divide in environmental knowledge and empathy between both variables creates a partisan ecological worldview and knowledge gap during a very critical time in our global health. Determining relationships between gender and academic discipline with consideration for environmental concern and knowledge will help identify gap between the groups. If variation is present between gender and college major it may be valuable in targeting environmental outreach. It is difficult to simply imply that gender or academic background impacts concern or knowledge singularly. People and their behaviors are shaped by many interacting variables and research needs to reflect the multivariate nature of human behavior. This paper aims to provide a framework to investigate multivariate dimensions of environmental concern and action.

Review of Relevant Literature 
Previous empirical research effectively exists in mostly separate single variant designs using either one of the independent variables (gender, academic major) and one of the dependent variables (environmental concern, environmental knowledge). Earlier studies have focused exclusively on the relationship between gender or college major on the environmental topics of concern or knowledge using many different psychometric instruments.

\section{Gender and the Environmental Concern and Knowledge}

Ample research has been conducted with respect to gender and environmental issues. These studies are the mixed findings and research designs. Prior research has established a range of results varying from females having a greater concern towards environmental problems to males possessing a greater knowledge base of environmental matters.

Prior empirical studies have established that females, in general, demonstrate a greater involvement and are more concerned with environmental issues (Brody, 1984, Tarrant and Cordell, 1997, Momsen, 2000 \& Ewert and Baker, 2001, McCright, 2010). On a global scale it has been observed females are more involved in environmental activism (Momsen, 2000). On a local scale, research in the United States has found that females are commonly more concerned about the environment but at the same time are less politically active on these issues when compared to males (McStay and Dunlap, 1983). Additionally, females were found to show more concern about environmental issues that pose threats to local communities (Brody, 1984). Tarrant and Cordell (1997) and Ewert and Baker (2001) found that females demonstrated a significantly higher environmental attitude-behavior correlation compared to males.

While some studies show that females demonstrate a greater concern over environmental issues there are other studies that nullify this conclusion. Two studies that looked at gender, scientific knowledge and attitudes towards the environment found that males scored higher with respect to scientific environmental knowledge but neither gender showed a greater concern for environmental issues (Hayes, 2001, Benton \& Funkhouser 1994). To add to this, a study that looked at knowledge and attitudes on the environment found that men more often responded correctly to academic questions about the environment (Holl, Daily, Daily, et. al., 1999). A similar study suggested that gender was statistically unrelated to environmental behavior (Ollie, Grendstad and Wollebaek, 2001). Mohai (1992) determined that females showed increased environmental concern compared to males but also demonstrated lower rates of activism. These findings contradict research that suggests females show a greater concern for environmental matters.

Gender relationships with respect to environmental concern and knowledge have not resulted in strong correlations for either variable. The previous empirical research has generated the perception that women are generally more concerned about environmental problems while men tend to be more knowledgeable with respect to various scales of aptitude. If these findings are common then one would suspect that this study would establish similar results with respect to the gender variable.

\section{College Major and Environmental Knowledge and Concern}

Previous research has determined persons with academic backgrounds in natural, physical and life sciences tend to be more knowledgeable and concerned about the environment. A few studies have found that those who are involved in non-science disciplines are equally knowledgeable on environmental aptitude scales but are still less concerned. 
Studies that affirm that students enrolled in science based majors are increasingly knowledgeable and concerned with the environment are sparse. Synodinos (1990) compared business and liberal arts students to a general student body on parameters of the environment. The study concluded that business students' verbal commitment, actual commitment, affect and knowledge about the environmental issues were significantly lower compared the general student population (Synodinos, 1990). Sherburn \& Devlin (2004) support this finding but compared student majors of economics and environmental studies. From these studies it cannot be concluded that individuals involved in science disciplines are both more concerned and knowledgeable about environmental issues.

A larger body of earlier empirical research has found that individuals in science disciplines have a greater concern and affinity towards environmental issues when compared to those in non-science disciplines. Ewert and Baker (2001) found that forestry and business students exhibited lower pro-environmental attitudes compared to traditional science disciplines. A study that surveyed a random population of students from varying academic backgrounds found that science related disciplines had stronger affinity towards environmental issues and concerns compared to non-science disciplines (Hodgkinson and Innes, 2001). Similar research concluded that science majors had a greater affinity towards environmental issues compared to non-science majors (Tikka, Kuitunen \& Tynys, 2000). Elaborating on these findings was a study that determined science and social science majors showed greater proportions of positive ecological attitudes compared to business and undecided majors (Ridener, 1999). These studies provide evidence that students in science related disciplines typically show more concern towards environmental issues.

There are some studies that negate the trend of business related disciplines demonstrating less aptitude on environmental knowledge scales. At the same time these studies still confirmed that non-science related disciplines still demonstrated less concern and affinity towards environmental topics. Benton (1994) examined environmental knowledge and attitudes of university business students compared to non-business students and found that business students were not less environmentally knowledgeable, but they did demonstrate less concern for the environment and less willingness to act in environmentally friendly ways. The study casts uncertainty that a relationship between discipline and environmental knowledge exists but reiterates that disparity between academic discipline and environmental concern.

The review of previous research with respect to college major and environmental concern and knowledge established two possible relationships between the variables in this study. One would expect that those involved within science disciplines would show a greater concern for the environment. A relationship between discipline and environmental knowledge is hard to establish based on prior research. One may also assume that no relationship may exist between the variables based on previous findings.

Environmental concerns and problems are an apparent issue that will be a part of every individual's future. Determining relationships between gender and academic discipline with consideration for environmental concern and knowledge will help identify possible gaps between the groups. If trends in the univariate findings translate to the multivariate research it can be hypothesized that females' majoring in science should demonstrate higher levels of environmental concern than all other groups. Additionally, male science majors should demonstrate higher levels of knowledge compared with all other groups. Given any level of variation between the variables it may be valuable information to identify groups that may require education to help gain a wider concern and knowledge of future environmental issues.

\section{Methodology}


The purpose of this study is to determine if a relationship exists between the variables of gender and college major and environmental concern and knowledge. The use of a two-way factorial MANOVA (Multivariate analysis of variance) will provide a rich context to explore the phenomenon under investigation. The use of this multivariate approach will provide an interaction effect that will assess the joint influence of gender and college major. Variables are further evaluated via ANOVA for relationship strength and ANCOVA (analysis of the covariance) to account for extraneous variables present within the study.

\section{Context and Sample}

The data for this study comes from a survey administered during a required interdisciplinary environmental issues course for all enrolled first-year university students at a large Mid-Atlantic four-year university. The data from this survey possesses the necessary information to address the research questions. The survey was administered in an online format.

The sample is representative of an urban mid-sized university located on the eastern seaboard of the United States. The response rate is adequate, 1,229 first-year University students participated in the survey out of approximately 1,800 students enrolled. This calculates to a participation rate of $68.3 \%$. The participants included 770 females and 459 males. College major analysis revealed 547 students identifying themselves as "non-science" majors, 489 "science" majors and 191 that were undecided. Of those who chose to identify their race 332 were African American, 7 were Native Americans, 85 were Asian, 56 were Hispanic and 662 were Caucasian, 97 chose not to identify with a racial background. Table 1 provides the frequencies of gender and college major.

Table 1.

Frequencies of Gender \& College Major

\begin{tabular}{l|ll}
\hline Variable & Frequency & Percent \\
\hline Gender & & \\
$\quad$ Female & 769 & 62.7 \\
$\quad$ Male & 458 & 37.3 \\
Total & 1,229 & $100 \%$ \\
College Major & & \\
$\quad$ Non-Science & 547 & 44.6 \\
$\quad$ Science & 489 & 39.8 \\
$\quad$ Undecided & 191 & 15.5 \\
Total & 1,229 & $100 \%$ \\
& & \\
& & \\
Gender*College major & & \\
Female*Non-Science & 377 & 30.7 \\
Female*Science & 278 & 22.7 \\
Female*Undecided & 114 & 9.3 \\
Male*Non-Science & 170 & 13.9 \\
Male*Science & 211 & 17.2 \\
Male*Undecided & 77 & 6.2 \\
Total & 1,227 & $100 \%$ \\
\hline
\end{tabular}

\section{Measures}

This study concentrates on four variables: gender, college major, environmental concern and environmental knowledge. The first variable, gender was measured by the participant's sex $(1=$ female, $2=$ male $)$. 
The second variable measured by the survey was college major. Choices reflected six academic colleges of Arts and Letters, Business, Education, Engineering, Health Sciences and Sciences. An additional choice of undecided was also presented. These selections were subsequently recoded in to three broader categories ( $1=$ non science, $2=$ science, $3=$ undecided). Respondents that chose the colleges Arts and Letters, Business or Education were coded in to "Non-Science" majors. The individuals that affiliated themselves with the colleges of Engineering, Health Sciences and Sciences were coded in to "Science Majors". The Undecided group was left alone as another unit of analysis.

The third variable measured by the survey reflected two environmental concern scales. The first scale was the Revised New Ecological Paradigm instrument (NEP) (Dunlap et al., 2000) that assesses attitudes towards the environment. The questions on this scale are mostly aimed at how respondents feel humans impact the environment and the current (and future) state of the earth. Previous research reported an internal consistency coefficient alpha of .83 for this scale (Dunlap et al., 2000). The second instrument was an environmental concern scale adapted from the survey of public attitudes to quality of life and to the environment (2001, Department of Environment Food and Rural Affairs, in England). This instrument is comprised of twenty items that describes different environmental issues and measures how concerned the participants are about various environmental problems such as acid rain and global warming. This assessment was calculated to possess an internal consistency alpha coefficient of (.94).

The last variable measured by the survey was environmental knowledge. A Total Environmental Knowledge scale of 24 academic based multiple response questions concerning environmental sciences and behaviors determined the participant's knowledge. The score on the scale was computed by having each question answered correctly garnering the individual with one point. The participant could not score above 25 points. The internal consistency alpha coefficient for overall environmental knowledge was computed to be (.70).

\section{Procedure}

The survey used in this study was administered in a one week period at the beginning of the fall semester in a digital format for use on the Internet. Students were asked to complete the online survey to earn extra credit and were given alternatives to participation for the credit. On the Sunday of the administration period the survey was emailed to the participants. The students were required to click a hyper link that leads them to the survey database. Upon doing this the individuals received the survey via an interactive web page. On this page participants were required to click appropriate response for each of the variables. Upon completion the individuals clicked submit and the results were submitted to a data bank for subsequent data screening and analysis.

\section{Data Screening}

Data screening procedures used prior to data analysis were frequency histograms to find missing cases and to determine if the data fell within a normal curve. In addition, a Mahalanobis distance analysis was performed to determine statistically significant outliers. There were no instances of a Mahalanobis distance greater than 3 or a probability less than 0.01 in the sample.

\section{Analytic Approach}

The data in this study is analyzed using a two way factorial MANOVA. This multivariate factorial design will examine the unique and joint effects of the two independent variables of gender and academic discipline on the two dependent variables of environmental concern and knowledge. The variables are subsequently analyzed collectively with the dependent variant (gender*college major) and separately on each dependent variable. 
The statistical procedure is used to determine relationships among the variables on both a multivariate and single variable level. Wilk's lambda will determine the statistically significant effects of the independent variables on the dependent variables and a one way analysis of the variance (ANOVA) will determine the locus of statistically significant main effects of each dependent variable on an individual basis. A (.95) confidence level is used to determine statistical significance. Lastly an analysis of the covariance was conducted to account for the variables race, housing status and grade point average.

\section{Findings}

Data screening found that no extreme outliers as determined by Mahalanobis Distance and frequencies determined that there were two missing cases. This resulted in having to delete two of the entries. A histogram of frequencies revealed a normal distribution. Mean scores for environmental concern (NEP \& ECS) and knowledge for the variables of gender and college major are presented in Table 2. Findings show that females on average were more environmentally concerned when measured by the environmental concern scale. This trend was apparent regardless of major. Males are shown to exhibit higher levels of environmental knowledge as are science and undecided majors in either gender.

Table 2.

Mean Scores of Environmental Concern (NEP \& ECS) and Knowledge

\begin{tabular}{l|lll}
\hline Dependent Variable & Independent Variable & Mean & Standard Error \\
\hline Environmental Concern Scale & Female & 3.744 & .022 \\
& Male & 3.539 & .028 \\
& Non-Science & 3.655 & .025 \\
& Science & 3.672 & .025 \\
& Undecided & 3.597 & .040 \\
& Female*Non-Science & 3.734 & .028 \\
& Female*Science & 3.772 & .032 \\
& Female*Undecided & 3.725 & .051 \\
& Male*Non-Science & 3.576 & .042 \\
& Male*Science & 3.571 & .037 \\
& Male*Undecided & 3.469 & .062 \\
& & & \\
& Female & 3.306 & .014 \\
& Male & 3.264 & .017 \\
& Non-Science & 3.282 & .016 \\
& Science & 3.297 & .015 \\
& Undecided & 3.276 & .025 \\
& & &. \\
& Female*Non-Science & 3.287 & 017 \\
& Female*Science & 3.312 & .020 \\
& Female*Undecided & 3.321 & .032 \\
& Male*Non-Science & 3.277 & .026 \\
& Male*Science & 3.282 & .023 \\
& Male*Undecided & 3.232 & .039 \\
& & & \\
& & 9.783 & .122 \\
& Female & 9.967 & .153 \\
\hline
\end{tabular}




\begin{tabular}{l|lll}
\hline & & & \\
& Non-Science & 9.701 & .138 \\
& Science & 9.845 & .137 \\
& Undecided & 10.07 & .221 \\
& Female*Non-Science & 9.732 & .154 \\
& Female*Science & 9.784 & .180 \\
& Female*Undecided & 9.833 & .281 \\
& Male*Non-Science & 9.671 & .230 \\
& Male*Science & 9.905 & .206 \\
& Male*Undecided & 10.33 & .341 \\
\hline
\end{tabular}

\section{Gender}

To measure gender differences on the dependent variables the first item computed was a Between-Subjects Factor analysis. This provides the sample size for each independent variable broken down by treatment or level. In this analysis it is noted that the independent variable of gender resulted in a large unequal sample size. For this variable the female gender had a sample size of $N=769$ and the male gender had a sample size of $N=458$.

After an investigations of interactions it was found that males that were undecided on their academic discipline scored an average of one level higher $(M=10.32)$ on their knowledge scale compared to all other males and females. Additionally, data revealed that overall women scored higher on the environmental concern scale regardless of academic discipline.

Box's test of equality of covariance matrix is statistically significant (Box's $M=31.80, p<$ $.05)$ therefore the covariance matrices are significantly different and so the homogeneity assumption has been violated. The effect of violating this assumption is unclear. Tabachnick and Fidell (1996) suggest that larger samples produce greater variances and covariance's and that probability values will be conservative. If these criterions are met then significant findings can be trusted. The large sample size of this study is conducive to these criteria and therefore the analysis will continue to look for significant findings and Wilk's lambda will be used to assess multivariate effects.

The multivariate main effect of gender is presented in Table 3. The analysis of this variable resulted in a Wilk's lambda value $=.971$, which is subsequently translated into a $F$ value of 18.24 and evaluated at a degrees of freedom of 2 for between groups hypothesis and error within groups of 1,220 . This $F$ value is statistically significant $(p<$ .000 ), indicating differences between the two genders and the dependent variables. The partial eta-squared value tells us that this effect accounts for $3 \%$ of the total variance.

Table 3.

Multivariate Main Effect of Gender via Wilk's Lambda

\begin{tabular}{l|llllll}
\hline Effect & $\begin{array}{l}\text { Wilk's } \\
\text { Lambda } \\
\text { Value }\end{array}$ & $F$ & $\begin{array}{l}\text { Hypothesis } \\
d f\end{array}$ & Error df & Sig. & $\begin{array}{l}\text { Partial Eta- } \\
\text { Squared }\end{array}$ \\
\hline Gender & .971 & 18.24 & 2.0 & 1,220 & .000 & .029 \\
\hline
\end{tabular}


Next, the main multivariate effect of academic discipline was examined and displayed in Table 4. The Wilk's lambda value of .996 is translated in to an $F$ value of 1.30 and evaluated at 4 and 2240 for between and within group's degrees of freedom. This $F$ is not statistically significant $(p>.005)$ and indicates that academic discipline does not likely effect environmental concern or knowledge. This multivariate main effect accounts for $2 \%$ of the variance.

Table 4.

Multivariate Main Effect of College Major via Wilk's Lambda

\begin{tabular}{l|llllll}
\hline Effect & $\begin{array}{l}\text { Wilk's } \\
\text { Lambda } \\
\text { Value }\end{array}$ & $F$ & $\begin{array}{l}\text { Hypothesis } \\
d f\end{array}$ & Error df & Sig. & $\begin{array}{l}\text { Partial Eta- } \\
\text { Squared }\end{array}$ \\
\hline $\begin{array}{l}\text { College } \\
\text { Major }\end{array}$ & .996 & 1.30 & 4.0 & 2240 & .267 & .02 \\
\hline
\end{tabular}

\section{Interaction of Gender \& College Major}

Lastly the combined multivariate effect of (gender*academic discipline) was examined and depicted in Table 5. This interaction produced a Wilk's lambda value of .998, which is translated in to an $F$ value .649 and evaluated with degrees of freedom of 4 and 2240 for between and within group's degrees of freedom. This $F$ is not statistically significant $(p>.005)$, indicating that the multivariate interaction effect of (Gender *Academic Discipline) does not account for a significant proportion of the variance.

Table 5.

Multivariate Main Effect of Gender and Academic Discipline via Wilk's Lambda

\begin{tabular}{l|llll}
\hline Effect & Wilk's Lambda Value & $F$ & Sig. & Partial Eta-Squared \\
\hline Gender* College Major & .997 & .693 & .656 & .002 \\
\hline
\end{tabular}

Since only the multivariate effect of gender was found to be statistically significant the analysis proceeded with a separate assessment of gender's main effect. This process starts with an inspection of Levene's test of equality of error variances shown in Table 6. The gender variable's main effect is significant $(p<.01)$ for environmental concern when measured with the ECS. Gender's effect was not significant for environmental concern (when measured with the NEP) and environmental knowledge. From this analysis we can now proceed with ANOVA's for gender and college major's effect on each dependent variable.

Table 6.

Levene's Test of Equality of Error Variances for Gender

\begin{tabular}{l|lll}
\hline Dependent Measure & $F$ & $d f$ & Sig. \\
\hline Environmental Concern Scale & 5.166 & 1227 & .000 \\
New Ecological Paradigm & .153 & 1227 & .138 \\
\hline Total Environmental Knowledge & .709 & 1227 & .444 \\
\hline
\end{tabular}


In the univariate analysis of gender and college major on each of the dependent variables it was found that only the interaction of gender and environmental concern was statistically significant $(p<.000)$. Table 7 depicts the Analysis of the Variance (ANOVA) for the independent variables (gender and college major) and their interaction with respect to the dependent variables (concern and knowledge). The data in combination with previous findings reflects that females were shown to score higher on the environmental concern scale and thus shown to have an increased concern about the environment when compared to males.

Table 7.

Analysis of the Variance between Gender \& College Major with Environmental Concern and Knowledge

\begin{tabular}{|c|c|c|c|c|}
\hline Scale & Independent Variable & $D f$ & $F$ & Sig. \\
\hline Environmental & Gender & & & \\
\hline \multirow[t]{7}{*}{ Concern Scale } & Between Groups & 10.582 & 36.182 & .000 \\
\hline & Within Groups & 358.850 & & \\
\hline & Total & 369.432 & & \\
\hline & College Major & .654 & 1.087 & .338 \\
\hline & Between Groups & 368.331 & & \\
\hline & Within Groups & 368.985 & & \\
\hline & Total & & & \\
\hline \multirow{8}{*}{$\begin{array}{l}\text { New Ecological } \\
\text { Paradigm }\end{array}$} & Gender & & & \\
\hline & Between Groups & .251 & 2.206 & .138 \\
\hline & Within Groups & 139.778 & & \\
\hline & Total & 140.030 & & \\
\hline & College Major & & & \\
\hline & Between Groups & .065 & .285 & .752 \\
\hline & Within Groups & 139.880 & & \\
\hline & Total & 139.945 & & \\
\hline \multirow{8}{*}{$\begin{array}{l}\text { Total Environmental } \\
\text { Knowledge }\end{array}$} & Gender & & & \\
\hline & Between Groups & 5.262 & .587 & .444 \\
\hline & Within Groups & 11005.695 & & \\
\hline & Total & 11010.957 & & \\
\hline & College Major & & .828 & .437 \\
\hline & Between Groups & 14.850 & & \\
\hline & Within Groups & 10970.661 & & \\
\hline & Total & 10985.511 & & \\
\hline
\end{tabular}

Lastly, an analysis of covariance (ANCOVA) was computed to account for inter-group variation that is not associated with the independent variables measured. Participant measures of race, housing status and grade point average were included as covariates and random factors. Outcomes from the calculation show that gender and college major are statistically significant only on the measure of environmental concern (when measured with ECS). Table 8 represents the analysis of the covariance between gender $\&$ college major and environmental concern. 
Table 8.

Analysis of the Covariance between Gender \& College Major and Environmental Concern

\begin{tabular}{l|llll}
\hline Variable & $\begin{array}{l}\text { Type III Sum of } \\
\text { Squares }\end{array}$ & $d f$ & $F$ & Sig. \\
\hline $\begin{array}{l}\text { Gender } \\
\text { Hypothesis }\end{array}$ & 3.447 & 1 & 14.438 & .000 \\
$\quad$ Error & 40.595 & 170.023 & & \\
& & & & \\
$\begin{array}{l}\text { College Major } \\
\text { Hypothesis }\end{array}$ & 1.941 & 2 & 3.055 & .049 \\
$\quad$ Error & 77.051 & 242.616 & & \\
\hline
\end{tabular}

\section{Results and Discusion}

This investigation sought to determine if a relationship exists between the independent variables of gender and academic discipline and the dependent variables of environmental concern and knowledge. Based on the results from the two-way factorial MANOVA it can be determined that a multivariate relationship between the variables does not exist with respect to this study. Combining factors such as gender and academic background provides a rich context to study environmental issues such as knowledge and concern. Narrowing the scope of investigated populations can make finding significant correlations or predictions much harder. However, it is important to account for the many factors that shape human behavior especially with respect to environmental issues. Considerable research suggests that environmental actions are influenced by a range of factors that are not fully appreciated by policymakers or researchers (Barr, 2003). Our actions are not only shaped by our gender and academic backgrounds but factors such as value systems, situational circumstances and psychological variables can all shape human behavior. Much of the previous research with respect to environmental knowledge and concern lacks the interconnection of these influencing factors. A hierarchy factors exists concerning environmental actions and stewardship. Foremost is the rationale that knowledge of environmental issues has a major impact on behavior (Barr, 2003). Environmental values (attitudes \& concern), situational dynamics (socio economic \& socio demographic) and psychological variables (motivation \& altruism) all have a secondary but important influence on environmental behaviors (Barr, 2003). Future research in environmental behavior and education should reflect the diverse backgrounds that comprise one's environmental mentality. The use of multivariate research in the field of environmental science, education and behaviors will allow for a more complete and detailed description of the phenomenon under investigation. Information gathered and studied should reflect the complexity of factors that shape our environmental behaviors and actions.

Findings did determine that a significant relationship does exist between the variables of gender and environmental concern. Females demonstrated a higher degree of environmental concern when measured on the Environmental Concern Scale. However, when covariates such as GPA, race and housing (on or off campus) were accounted for it was determined that college major was significant in shaping environmental concern. Those pursuing traditional science degrees expressed increased levels of environmental concern when measured on the Environmental Concern Scale. Environmental knowledge was shown to favor males that were undecided or pursuing a science major in test score distribution but is not valid given the large differences in participation rate. Insignificant differences existed between the other variables. 
These findings suggest that future research could focus on gender differences respect to other aspects of environmental issues such as motivation, altruism or policy opinions. As environmental issues move to the forefront of federal and state government agendas the voices of concern should be heard and respected. The differences found in college majors and their concern for the environment warrants further investigation. Environmental education initiatives may be valid if perceptional differences become increasingly apparent between science and non-science majors. College graduates are future leaders in industry and government and environmental literacy is important to ensure that future actions account for environmental health.

Lastly, the implementation of a multivariate design provided a rich context for exploring multiple variables associated with environmental knowledge and concern. In addition, considering that all participants were first-year University students an academic study that focused on individuals further along in their academic pursuits or in older age brackets may determine a greater difference in knowledge aptitudes and environmental behaviors. In any case, future research in environmental behaviors and education needs to reflect the multifaceted backgrounds that shape one's actions.

\section{References}

Barr, S. (2003). Strategies for sustainability: citizens and responsible environmental behavior. Area 35, 3, 227-240.

Benton, R. (1994). Environmental knowledge and attitudes of undergraduate business students compared to non-business students. Business \& Society, 33, 2, 191211.

Benton, R. \& Funkhouser, G.R., (1994). Environmental attitudes and knowledge: an international comparison among business students. Journal of Management Issues 6 3, pp. 366-381.

Brody, C. J. (1984). Differences by sex for support of nuclear power. Social Forces, 3 , 209-228.

Department for Environment, Food, and Rural Affairs (2001). Survey of public attitudes to quality of life and the environment. Retrieved from http://www.dataarchive.ac.uk/findingdata/sndescription.asp?sn=4741.

Dunlap, R., Van Liere, K., Mertig, A., \& Jones, R. (2000). Measuring endorsement of the New Ecological Paradigm: A revised NEP scale. Journal of Social Issues, $56(3), 425-442$.

Ewert, A. \& Baker, D. (2001). Standing for where you sit: An exploratory analysis of the relationship between academic major and environmental beliefs. Environment and Behavior, 33, 687-707.

Hayes, B. (2001). Gender, scientific knowledge and attitudes toward the environment: A cross-national analysis. Political Research Quarterly, 54, 3, 657-671.

Hodgkinson, S. Innes, M. (2001). The attitudinal influence of career orientation in $1^{\text {st }}$ year university students. The Journal of Environmental Education, 32, 3, 37-40

Holl, K., Daily, G., Daily, S., Ehrlich, P., \& Bassin, S. (1999). Knowledge and attitude toward population growth and the environment: University students in Costa Rica and the United States. Environmental Conservation, 26, 1, 66-74. 
McCright, A. M. (2010). The effects of gender on climate change knowledge and concern in the American public. Population and Environment, 32(1), 66-87.

Mcstay, J. R. and Dunlap, R. E. (1993). Male-female differences in concern for environmental quality. International Journal of Women's Studies, 6, 291-301.

Mohai, P., (1992). Men, women, and the environment: an examination of the gender gap in environmental concern and activism. Society and Natural Resources 5, pp. 119.

Momsen, J. (2000). Gender differences in environmental concern and perception. Journal of Geography, 99, 2, 47-56.

Olli, E., Grendstad, G., \& Wollebaek, D. (2001). Correlates of environmental behaviors. Environment and Behavior, 33, 3 181-201.

Ridener, L. (1999). Effects of college major on ecological world views: A comparison of business, science and other students. Journal of Education for Business, 75, 1, 15-21

Sherburn, M. \& Devlin, A.S. (2004). Academic major, environmental concern and arboretum use. Journal of Environmental Education, 35(2), 23-36.

Synodinos, N. (1990). Environmental attitudes and knowledge: A comparison of marketing and business students with other groups. Journal of Business Research, 20, 2, 161-170.

Tabachnick, B. G., \& Fidell, L. S. (1996). Using multivariate statistics (3rd Ed.). New York: Harper Collins Wilkinson

Tarrant, M. A., \& Cordell, H. K. (1997). The effect of respondent characteristics on general environmental attitude-behavior correspondence. Environment and Behavior, 29, 618-637.

Tikka, P. Kuitunen, M. Tynys, S. (2000). Effects of educational background on student attitudes, activity levels and knowledge concerning the environment. The Journal of Environmental Education, 31, 3, 12-19. 